\title{
RUPTURED CONGENITAL ANEURYSM OF THE POSTERIOR SINUS OF VALSALVA
}

\author{
BY \\ R. N. HERSON AND M. SYMONS \\ From the Departments of Medicine and Pathology, University of Bristol
}

Received April 6, 1946

The three sinuses of Valsalva are best described as right, left, and posterior, the last being the non-coronary sinus. An aneurysm may develop in relation to any of these, but the right sinus is the one most usually involved; the aneurysm then generally ruptures into the right ventricle. The posterior sinus is far less often implicated. It comes into close anatomical relationship to the right atrium, into which an aneurysm of this sinus is likely to rupture. Symptoms are unusual until shortly before death, which is often sudden, through perforation into the pericardium, pulmonary artery, right atrium, or ventricle. Those aneurysms that enlarge to the right may cause conduction disturbances by their proximity to the membranous portion of the interventricular septum.

Syphilis, ulcerative endocarditis, and atheroma are recognized causes of dilatation of the aortic sinuses, but the condition also occurs as a rare congenital anomaly. Abbott (1936) was able to collect records of 12 congenital cases; Micks (1940) described a case of congenital aneurysms of all three sinuses; while Hirschboeck (1942) reported an aneurysm of the right sinus, and Macleod (1944) one of the left. Brown (1939) mentioned two cases, in one of which the aneurysm arose from the right sinus and in the other from all three; in both these rupture occurred into the pericardium: he stated that in about half the congenital examples there was an additional defect of the bulbar septum just below the aneurysm.

\section{REPORT OF A CASE}

A housewife, aged 31, was admitted to Southmead Hospital on February 6, 1946, with symptoms and signs of heart failure.

At the age of 12, because she had had frequent fainting attacks, she was referred to Dr. Coombs at the Bristol Royal Infirmary. On examination he found that the apex beat was normal in position and extent. Pulsation was felt in the epigastrium. A loud musical systolic murmur was heard over the whole of the præcordium, maximal at the inner ends of the fourth and fifth spaces; it could also be heard between the left scapula and the spine. There was no cyanosis and no clubbing of the fingers. An X-ray did not show any cardiac enlargement, and the cardiogram was normal. There was no history to suggest rheumatic fever. Seen again a year later by Dr. Coombs, her condition was found to be unchanged. He considered the heart lesion to be congenital.

The patient herself was adamant that until two weeks before admission to hospital she was able to indulge in all normal activities without symptoms. She had passed through three labours without undue distress, and in none had she to take to her bed before the actual onset of labour pains. She had a vague recollection of having attended a cardiac clinic in youth but understood that she had outgrown her heart trouble.

Two weeks before admission, whilst sawing wood, she experienced a sudden, acute pain behind the lower part of the sternum, which radiated upwards into the throat and gave her a choking sensation. Because of the severity of the pain, and the repeated vomiting which soon accompanied it, she was forced to go to bed. The pain and vomiting continued for the following two days. She became increasingly short of breath and her legs and abdomen began to swell. Insomnia became troublesome.

On admission she was found to be dyspnœic. Her face was pale except for slight cyanosis in the cheeks and lips. There was engorgement of the cervical veins and those coursing over the upper part of the chest; these vessels showed pulsation. The apex beat was in the sixth space, two inches outside the mid-clavicular line. No thrills were felt. The heart was beating regularly at the rate of 120 a minute. All over the præcordium there was a rough, roaring systolic and a diastolic murmur. This was much louder over the tricuspid area than anywhere else, but it was also very loud over the 
mitral area. Listening over the aortic area and along the left border of the sternum it was difficult to decide whether the murmurs heard were conducted from the tricuspid area or whether they were different in character and originating from the aortic valve. The blood pressure was 200 systolic, and $\mathbf{4 0}$ diastolic. There was dulness over both lung bases with diminished air entry and crepitations, more so on the right. There was a moderate amount of free fluid in the abdomen. The liver was enlarged three fingers' breadth below the costal margin, and could be felt to pulsate. The spleen was not palpable. There was gross œdema of the legs and the small of the back.

An antero-posterior X-ray of the chest, taken with a portable machine, showed gross dilatation of the heart and an opacity at the base of the right lung. A cardiogram revealed a regular A-V nodal rhythm at a rate of 120 a minute, and right ventricular preponderance (Fig. 1). The hæmoglobin

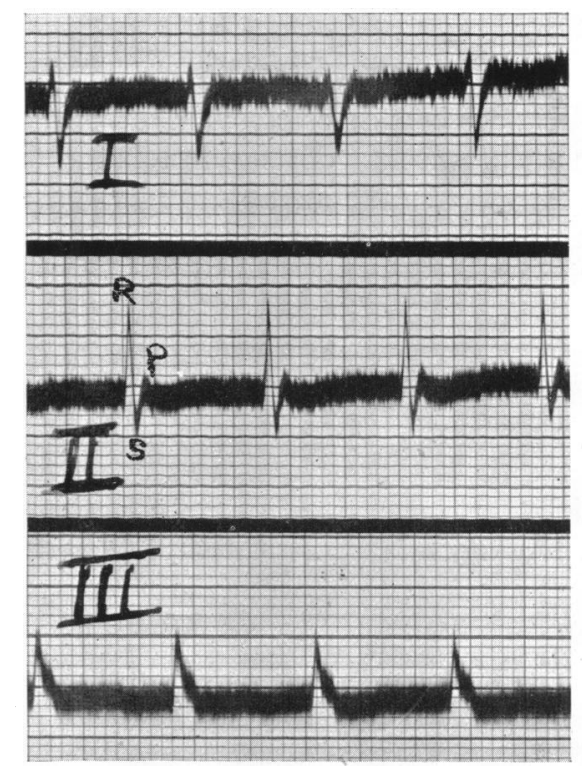

FIG. 1.-A-V nodal rhythm and right axis deviation. The heart is beating regularly at a rate of 120 a minute.

was 78 per cent (Haldane), the red blood corpuscles $4,400,000$, and the white blood corpuscles 14,000 per cu. mm. Carotid and eyeball pressure had no effect on the cardiac rate. Treatment with restricted fluid and salt intake, full doses of digoxin, injections of mersalyl, and with sedatives produced no improvement, and had very little effect on the cardiac rate. The œedema and effusions into the serous cavities increased-the ascites had to be tapped. On February 25 her conjunctivæ were slightly jaundiced and urinary output was poor. She died rather suddenly at about noon on this day, shortly after addressing a remark to one of the nurses.

Post-mortem examination was performed 24 hours after death.

The body was well nourished, there was slight jaundice present and generalized venous engorgement with anasarca.

The abdominal and pleural cavities contained a large quantity of bile-stained fluid and the pericardial cavity also contained a slight excess of similar fluid.

The heart weighed $385 \mathrm{~g}$. The right side was considerably dilated; the right atrium communicated with the left through a small aperture in the fossa ovalis; beneath this, lower down the interatrial septum and just above the septal cusp of the tricuspid valve, there was a saccular projection of thin membrane in the centre of which was a small hole $1 \mathrm{~mm}$. in diameter; there was also a ragged perforation of this aneurysmal sac through a calcified part of its wall (Fig. 2). In the anterior margin of the septal cusp of the tricuspid valve there was a foramen $3 \mathrm{~mm}$. in diameter leading directly into the left ventricle. The margins of the valve adjacent to this aperture were thickened and slightly discoloured: this was presumably due to the mechanical stress of the jet of blood entering from the left ventricle. The valve measured $13 \mathrm{~cm}$. in circumference and appeared competent.

The right ventricular wall measured $7 \mathrm{~mm}$. in thickness and the chamber appeared somewhat dilated. The pulmonary valve was normal.

The left atrium was not remarkable.

The mitral valve measured $9 \mathrm{~mm}$. in circumference and was healthy. 
The left ventricular wall measured $15 \mathrm{~mm}$. in thickness and was not dilated or hypertrophied. Just below the point of fusion of the right and posterior cusps of the aortic valve there was a foramen opening through the anterior margin of the septal cusp of the tricuspid valve as described above.

The aortic valve was deformed; the right and posterior cusps were partially fused and there was a small fenestration in the free margin of the right cusp. The adjacent parts of these cusps were thickened (Fig. 3), but there was no generalized thickening as seen in rheumatic valvulitis. The valve

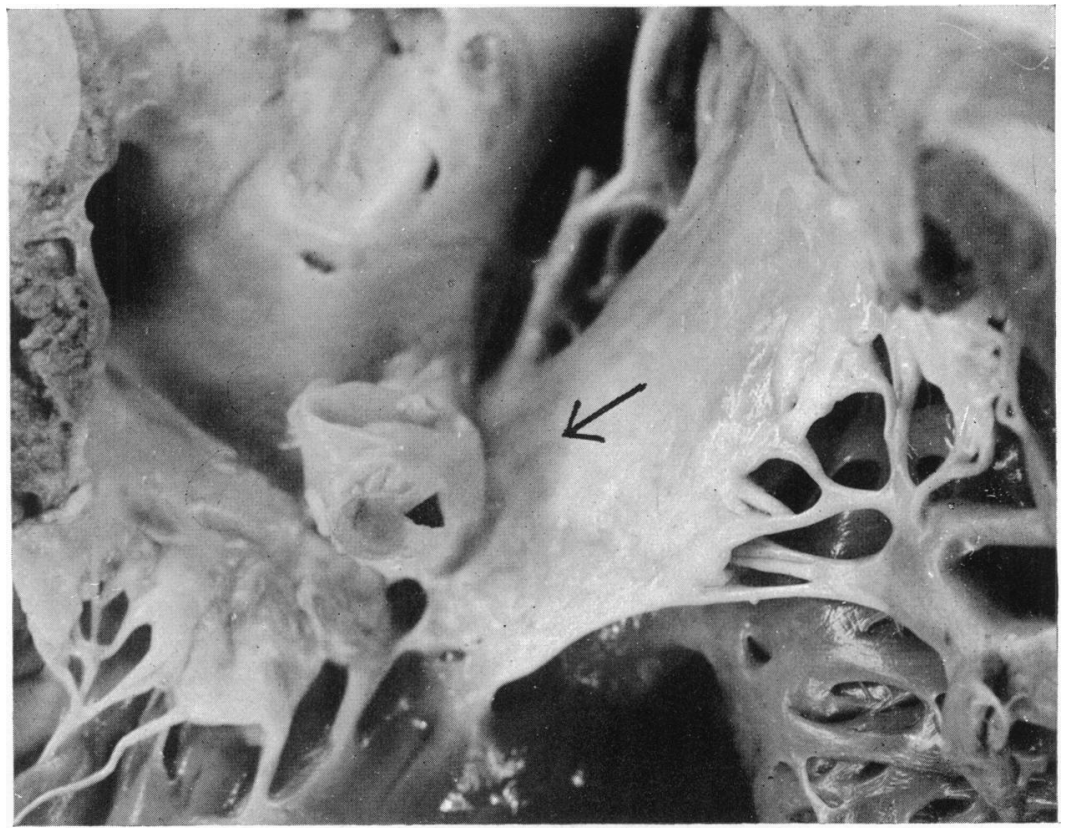

Fig. 2.-View of right atrium and tricuspid valve. The arrow points to the ruptured aneurysm with the orifice of the patent interventricular septum immediately below it. Note the roughening of the tricuspid leaflets. Magnification $\times 1.4$.

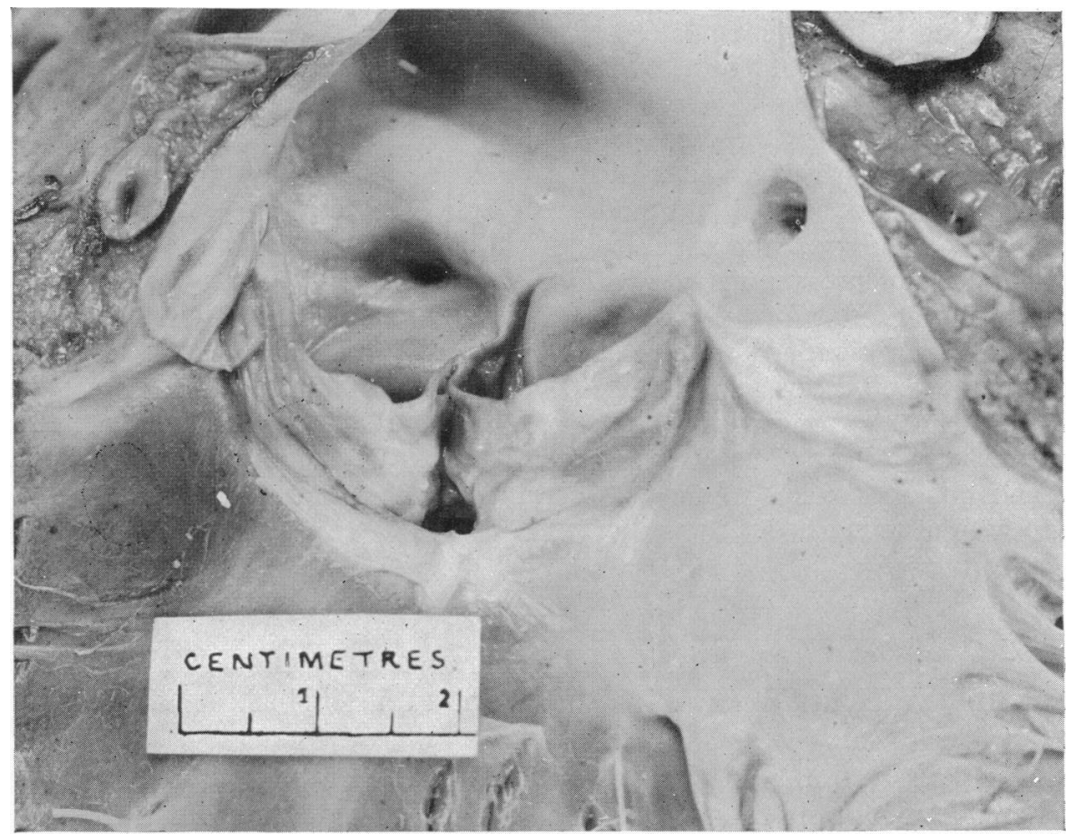

FIG. 3.-Aortic valve. The sinuses of Valsalva enumerated from left to right are: right, posterior, and left. The interventricular septal defect lies immediately below the fused right and posterior cusps. Magnification $\times 1.4$. 
measured $6 \mathrm{~cm}$. in circumference (normal $8 \mathrm{~cm}$.). The right sinus of Valsalva was considerably dilated and stretched back into the muscle of the interventricular septum. The floor of the posterior sinus of Valsalva consisted of an aneurysmal sac leading into the right atrium (Fig. 4). The left sinus of Valsalva was normal.

There was no evidence of any rheumatic or infective endocarditis, past or present.

There was slight atheroma of the abdominal aorta. The left renal vein passed behind the aorta.

Both lungs were very congested and moderately œdematous.

The spleen was not enlarged and appeared normal on section.

The liver showed intense venous congestion, and histologically there was considerable central necrosis, sufficient to account for the jaundice. There was no evidence of chronic congestion.

The gall-bladder and bile ducts were healthy and patent.

Both kidneys showed venous congestion. There was a double ureter on the left side.

Anatomical diagnosis. Congenital aneurysms of the right and posterior aortic sinuses of Valsalva with rupture of the posterior sinus into the right atrium. Patent interventricular septum. Fusion of the right and posterior cusps of the aortic valve. Right ventricular hypertrophy. Congestive cardiac failure with terminal hepatic jaundice.

\section{Discussion}

Some writers (Goehring, 1920) have considered a deformity of the aortic valve cusps similar to ours to be a bicuspid valve, but this is not admissible as the adjacent raphé between the right and posterior cusps was still present.

Histological examination of the liver showed that the venous congestion was of recent origin, and it seems probable therefore that it dated approximately from the time of rupture of the aneurysm.

The sudden onset with pain, shock, and vomiting, signs of aortic insufficiency, and the rapid development of heart failure in a previously healthy subject characterize most of the 
detailed reports of this condition. This clinical picture may also be produced by rupture of an aortic valve cusp and sometimes by a dissecting aneurysm involving the aortic ring. As in coronary occlusion, leucocytosis and even elevation of the temperature may be found. In both the case reported by Micks (1940) and in that by Duras (1944) there was heart block. Other conduction disturbances have been recorded.

In many of the reports the clinical details are scanty, because of the rapidity with which death follows rupture. Both Hirschboeck (1942) and Macleod (1944) reported rupture of an aortic sinus into the right atrium; in both these cases and in our own the clinical pictures were very similar.

In the case reported by Hirschboeck the aneurysm arose from the right sinus of Valsalva. There was a systolic thrill over the apex, and a harsh systolic murmur was audible at the lower end of the sternum and in the epigastrium. On admission the blood pressure was $300 / 0$ and the heart rate was 140 a minute. Liver dulness extended about two fingers' breadth below the costal margin. The leucocytes were counted on two occasions-on the first occasion the count was 11,400 per cu. $\mathrm{mm}$. and on the second 18,800 per cu. $\mathrm{mm}$. The temperature fluctuated from normal to $103^{\circ} \mathrm{F}$. Five days after admission a diastolic murmur was heard at the base and along the left border of the sternum. A diagnosis of aortic and tricuspid insufficiency caused by endocarditis of undetermined origin was made. Right axis deviation had been found in the cardiogram and in view of the extreme hypertension this was considered to be unusual. Macleod described the onset of symptoms in his patient as sudden with abdominal pain, vomiting, and breathlessness. A harsh systolic murmur was heard all over the heart, loudest in the aortic area, and at the right border of the sternum there was a soft diastolic murmur. There was a water-hammer pulse, and engorgement and pulsation of the veins of the neck. A cardiogram showed auricular fibrillation. Necropsy, five weeks after onset, revealed an aneurysm of the left sinus of Valsalva, which had ruptured into the right atrium.

In our case the murmur noted in childhood was no doubt due to the communication between the left ventricle and the right atrium. This lesion does not appear to have caused any gross functional disturbance.

The sudden onset of symptoms can best be explained by rupture of the posterior sinus of Valsalva into the right atrium. The loading of the right atrium with blood from the aorta during auricular diastole explains the venous congestion and the pulsation in the veins of the neck and liver, while the same leak of blood out of the aorta accounts for the marked water-hammer pulse. The roaring systolic and diastolic murmur, heard best over the tricuspid area, is also accounted for by the anatomical findings. From a functional point of view a similar disturbance of cardiac dynamics would result from a combination of tricuspid and aortic regurgitation, and this was the diagnosis during life.

The A-V nodal rhythm was probably due to irritation of the A-V node by the aneurysm. The right axis deviation is readily understood, and as pointed out by Hirschboeck (1942), may have some diagnostic value when coupled with a water-hammer pulse. If the existence of such a lesion is borne in mind diagnosis after rupture is sometimes feasible.

Our thanks are due to Dr. Phillips, Medical Superintendent, Southmead Hospital, Bristol, for permission to publish this case; and to Professors Perry and Hewer for helpful criticism. We should also like to thank Mr. S. A. Edwards for the photographic reproductions.

\section{REFERENCES}

Abbott, M. E. (1936). Atlas of Congenital Heart Disease, New York. Brown, J. W. (1939). Congenital Heart Disease, London.

Duras, P. F. (1944). Brit. Heart J., 6, 61.

Goehring, C. (1920). J. Med. Research, 42, 49.

Hirschboeck, F. J. (1942). Amer. Heart J., 24, 550.

Macleod, A. (1944). Brit. Heart J., 6, 194.

Micks, R. H. (1940). Ibid., 2, 63. 